\title{
Hospital Warehouse Management during the construction of a new building through Lean Techniques
}

Carlotta Patrone ${ }^{*}, 1$, Maryna Mezzano Kozlova ${ }^{2}$, Monica Brenta $^{3}$, Francesca Filauro ${ }^{4}$, Donatella Campanella ${ }^{4}$, Antonietta Ribatti ${ }^{5}$, Elisabetta Scuderi ${ }^{5}$, Tiziana Marini ${ }^{6}$, Gabriele Galli², Roberto Revetria ${ }^{2}$

${ }^{1}$ E.O. Ospedali Galliera, General Directorate, Mura delle Cappuccine 14, 16128, Genoa, Italy

${ }^{2}$ University of Genoa, Mechanical, Energetic, Industrial and Transport Engineer Department (D.I.M.E.), Via Montallegro 1,16145 Genoa, Italy

${ }^{3}$ E.O. Ospedali Galliera, Anaesthesia Department, Mura delle Cappuccine 14, 16128, Genoa, Italy

${ }^{4}$ E.O. Ospedali Galliera, Pharmacy, Mura delle Cappuccine 14, 16128, Genoa, Italy

${ }^{5}$ E.O. Ospedali Galliera, Warehouse and Supply Department, Mura delle Cappuccine 14, 16128, Genoa, Italy

${ }^{6}$ E.O. Ospedali Galliera, Information and Technology Department, Mura delle Cappuccine 14, 16128, Genoa, Italy

\begin{tabular}{l} 
A R T I C L E I N F O \\
\hline Article history: \\
Received: 22 October, 2019 \\
Accepted: 23 December, 2019 \\
Online: 27 January, 2020 \\
\hline Keywords: \\
Business Process Reengineering \\
(BPR) \\
Lean \\
Management \\
Warehouse \\
Supply Chain Resiliency \\
Design of Experiments \\
Healthcare \\
\end{tabular}

\begin{abstract}
A B S T R A C T
This paper shows a method applied during the reconstruction of an existing middle size Italian hospital. In fact, during this delicate phase, the project had a significant decrease in storage space and access gates for goods, medicines and medical devices. This aspect has a negative impact on road traffic. There was no consensus among the management on how to deal with this problem. In addition, a great tension between engineers and warehouse managers made it impossible to find a solution. For the best of our knowledge there is no available literature on this topic. Hence, a deep analysis had been carried out according to the Business Process Reengineering (BPR). For this reason, a hospital lean group has been created and a statistically study on storage volume inside the warehouse and a monitoring of trucks and goods arrival has been implemented. Three different solutions had been identified through data collection, design of experiments and lean application. The first one was focused on an exclusively internal management, the second one on an exclusively external management whereas the last one was focused on a partially internal scenario. Advantages, disadvantages, costs and the impact on the road traffic has been highlighted for each scenario. Afterward the Management had all the elements to make the best decision. The method reported in this study could be extended during the construction or reconstruction of any company that needs a warehouse or to face a problem in a tense atmosphere.
\end{abstract}

\section{Introduction}

Warehouse management inside hospitals has always been considered a crucial topic. Venkateswaran highlighted the complexity of the management of drugs warehouses for the uncertain demand and the high risk of product unavailability that could potentially compromise the safety of the patients [1]. One of the more critical issues is the difficulty to apply Lean Technologies inside the warehouse. According to Frank, warehouses and Lean

${ }^{*}$ Corresponding Author Carlotta Patrone, E.O. Ospedali Galliera (Italy), patronecarlotta@gmail.com, +390105632975

www.astesj.com

https://dx.doi.org/10.25046/aj050132 are considered as mutually exclusive due to the strong difficulties of application of this method in a stockage setting. Nonetheless, the potential advantages are to reduce the "non-value-added steps" as much as possible and to optimize the stock flow [2].

This paper has been developed during the construction of a new building and the main target subjects were the office supply, the medical devices and the drugstore warehouse of an Italian highly specialized hospitals (430 beds). Moreover, during this period, the warehouse and the entry have been involved in the building site. More in detail, the project had a significant decrease in storage 


\section{Patrone et al. / Advances in Science, Technology and Engineering Systems Journal Vol. 5, No. 1, 256-262 (2020)}

space and access gates for goods, medicines and medical devices to the hospital had declined dramatically with an intense impact on the road traffic. In addition, there was no consensus among the management on how to deal with this problem. Furthermore, a great tension between engineers and warehouse managers made it impossible to find a solution. No study in a similar setting has been found in the literature. Therefore, it was necessary to analyze the most appropriate solution for the warehouse management during the construction phase to give to the management all the elements to choose the best solutions.

A deep analysis has been performed and then structured into two different phases, according to Business Process Reengineering (BPR). This paper is organized into five sections. Section 2 provides a literature review of the three main techniques used to develop this study. The methodology followed during the new building construction has been introduced in section 3 . Section 4 illustrates the results obtained whereas the conclusions have been presented in section 5 .

\section{Literature Review}

A review of the literature has been performed through the following keywords: "supply chain resiliency", "lean healthcare" and "lean warehouses".

\subsection{Supply Chain Resiliency}

Supply Chain Resiliency has been defined in a multidisciplinary view as "the adaptive capability of the supply chain to prepare for unexpected events, respond to disruptions, and recover from them by maintaining continuity of operations at the desired level of connectedness and control over structure and function" [3]. From a different point of view, another definition is "The ability of a system to return to its original state or move to a new, more desirable state after being disturbed" [4]. A resilient supply chain must respect the following principles:

- Resilience: it must be part of the initial project and the base of any decision. In other words, it has to be transversal to each side of the company. It is essential a high grade of risk collaboration and the resulting agility in the processes and their connection.

- Reactivity: The company must be ready to quickly respond to the unpredictable events in the most optimal way possible [5]. An efficient company has to work continuously on the vulnerability reduction, decreasing the probability of breakage and enhancing the resilience of their processes. This may occur by increasing the redundancy (increasing the cost) or the flexibility based on the organization of day-to-day operations [6]. Frequently the decision concerning the use of the resilience engineering method and Lean technique is doubtful [7].

\subsection{Lean Warehouse Management in healthcare}

The Lean has found widespread use in the healthcare sector. Its first hospital application occurred in 2001 in the United Kingdom and the next year in the United States [8]. In 2009, in Canada, five organizations found a way to increase the organization with outstanding results thanks to Lean. Consequently, it has been possible to decrease the waiting time both for the emergency rooms and for medical visits. Moreover, the operating and radiological room utilizations has been enhanced as well as the infectious diseases control [9].

Lean is an appropriate technique to tackle the materials inside the hospitals. A comparison study between the traditional storage and the Lean approach applications has been performed. The collecting data through questionnaires has been used and further statistical analysis has been performed [10]. Another suitable technique is the VIC strategy. This method is based on a mapping of the values flow (V), an integration of the stock information (I) and a final control (C) on these [11]. The flow mapping follows the production path from its start to its end and it shows a visual representation of the material flows and their information in each process [2].

In order to obtain better inventory management performances, the Customer Managed Inventory / Inventory Managed Inventory method (CMI/VMI) could be introduced inside the hospital. $\mathrm{VMI} / \mathrm{CMI}$ are cooperation forms between a supplier and a client [12].

An improvement system of the warehouse management has been introduced in a hospital in Michigan and it is called "two-bin supply chain system". For each specific medical supply, two containers were provided. This system has been designed in order to reduce the necessary time for the warehousemen to perform the inventory and to decrease the trends of an excessive order [13]. Still inside the hospital warehouse a comparison study between the $5 \mathrm{~S}$ traditional and the $5 \mathrm{~S}$ hybrid process has been implemented. $5 \mathrm{~S}$ is a sequence of activities (sort, set in order, shine, standardize and sustain) and it is demonstrated as an effective tool for the supply management or organization. On the other hand, the hybrid $5 \mathrm{~S}$ contains inventory management and process improvement tool techniques [1]. In order to manage the warehouses in a quicker and more accurate way it is possible to reinforce the Lean techniques using Radio Frequency Identification (RFID) technologies [14].

Studies focused on the warehouse personnel and on their sensitization about the downtimes have been treated. This waste of useful time could be used for other important procedures inside the hospital [10]. In order to sensitize the personnel, it is possible to introduce the Continuous Positive Reinforcements (CPR) technique. This is a management system using continuous positive reinforcement to achieve the objectives of the working groups [15].

The hospital warehouse management through the Lean application has been successfully described in study developed in province of Parma [16]. Two cases have been analyzed. The purpose of the first one was the cooperation among the hospitals in the region, including an exchange of drugs, medical devices etc., utilizing the same archive software in order to optimize the reorder and the storage process inside each hospital. The second case analyzed was an external centralized warehouse for all the hospitals in the province [16].

Another system adopted in China is based on a partial externalization of the hospital warehouses. It's called the inventory 
pooling. In other words, the hospital maintains the inventory minimum level, normally for 1 or 2 days of demand while most of the inventory is retained in the distribution center. The external warehouse organizes the daily deliveries of the drugs based on the information shared real-time by the hospital [17].

\subsection{Business Process Reengineering (BPR)}

The BPR has spread above all in the Anglo-Saxon world in the early 90 s in the private firm sector. In those years, one of the first definition of process reengineering has been provided by Hammer in a paper appeared on Harvard Business Review [18]. In this definition, the author defines this technique as "the substantial afterthought and the radical redesign of the business processes for the purpose to obtain relevant results in terms of quality and services improvements to the user and enhancement in the productivity (cost reduction in view of a volume rise of the performance provided)" [19]. Later, around the middle of 90s, some publications based on this approach started also in the healthcare sector. The BPR in a managerial approach for the management of the organizational change based on the logic for processes.

\section{Methodology}

One of the key success factors of the BPR implementation is the human involvement [20]. For this reason, a dedicated hospital Lean group has been created. The group is composed of warehouse managers, industrial engineers, civil engineer, architect, nurses, physician, IT technician, and pharmacists.

The authors followed the BPR steps.

\subsection{AS IS}

The first step was to detect the actual warehouse management with the relative data. The Lean group mapped the flow through the Value Stream Mapping (VSM) technique. Thereafter, a data collection has been implemented in order to detect:

- actual storage space and the number of goods access available;

- real utilization of the dedicated space and of the access.

The actual storage space is $1.631,25 \mathrm{~m} 2$ with two dedicated goods access available. It seems to be an easy task but the actual storage spaces are scattered and they are managed by different heads.

For the second purpose a six weeks data detection on storage volume trend and truck arrival has been carried out.

For an accurate data collection, the warehouses have been divided in different areas. Moreover, a monitoring of the truck arrival and departure times, the volume and the timing of the merchandise arrival and the various necessary controls have been performed. Microsoft Excel tables have been created to achieve an efficient collection.

Figure 1 shows a focus on the volume storage trend and Figure 2 illustrates the comparison between standard deviation, mean and the true value of the volume.

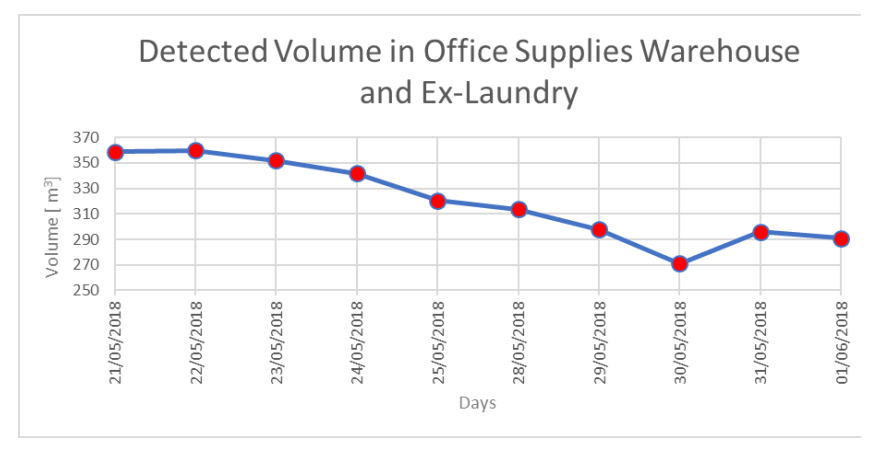

Figure 1: Storage in Office Supplies Warehouse and Ex-Laundry.

Comparison between Real Values, Average and Standard deviation, Office Supplies Warehouse

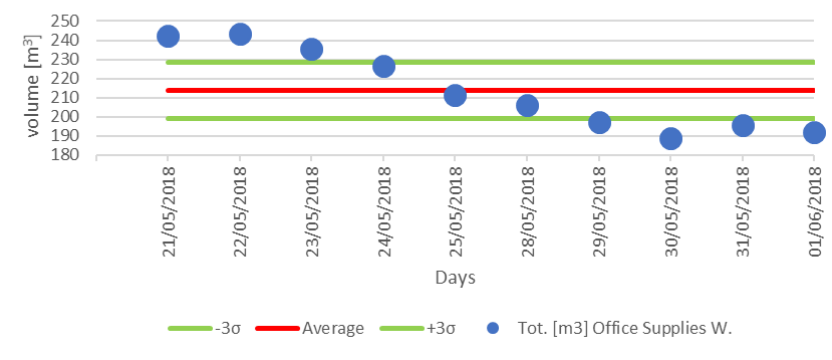

Figure 2: Comparison among Real Values, Average and Standard Deviation, office supplies warehouse.

An additional study based on the filling percentage of the space has been performed and reported in Table 1 . This means that many area and shelves do not occupy most of the available space. In parallel to this phase, the template for the arrival of trucks has been filled in. Two different good access are available: one dedicated to the office supply warehouse and other to the pharmacy.

Table 1: Percentage of filling, current state of the warehouse

\begin{tabular}{cccc}
\hline & $\begin{array}{c}{\left[\mathrm{m}^{3}\right]} \\
\text { occupied }\end{array}$ & $\begin{array}{c}{\left[\mathrm{m}^{3}\right]} \\
\text { available }\end{array}$ & \% occupied \\
\hline Shelves & 80,09 & 273,15 & $29 \%$ \\
Corridor & 20,84 & 74,54 & $28 \%$ \\
and Atrium & & & \\
Pallet & 140,41 & 288,54 & $49 \%$ \\
Rooms & & & \\
003-007- \\
009
\end{tabular}


C. Patrone et al. / Advances in Science, Technology and Engineering Systems Journal Vol. 5, No. 1, 256-262 (2020)

A statistical analysis has been performed to understand if the time slot or the day of the week or the week affect the truck arrival. Latin Square is applied when disturb factors occur in addition to the treatments and to the first disturb factor [21].

Concerning the data analysis of the truck monitoring of the office supply warehouse, the results of the Latin Square Method highlighted a significant difference in the truck arrival by changing the time slots. Day and week did not affect the truck arrival. The results are reported in Table 2 .

Table 2: Latin Square Method

\begin{tabular}{crrl}
$\begin{array}{c}\text { Source of } \\
\text { Variation }\end{array}$ & \multicolumn{1}{l}{$\mathrm{F}_{0}$} & $\mathrm{~F}_{0,05 ; 4 ; 12}$ & Conclusions \\
\hline Weeks & 0,81 & 3,26 & $\mathrm{~F}_{0}<\mathrm{F}_{0,05 ; 4 ; 12}$ \\
Time slots & 7,70 & 3,26 & $\mathbf{F}_{\mathbf{0}}>\mathbf{F}_{\mathbf{0}, 05 ; 4 ; 12}$ \\
Days & 2,27 & 3,26 & $\mathrm{~F}_{0}<\mathrm{F}_{0,05 ; 4 ; 12}$ \\
\hline
\end{tabular}

Analysis of Variance (ANOVA) has been performed on that data because only time slots affected the results. ANOVA is a set of statistic techniques whom are part of the inferential statistic. Moreover, they allow to analyze two or more groups of data by comparing the intern variability of these groups with the variability among these [22]. The ANOVA results for the office supply warehouse has been reported, as an example, in the Table 3 and 4. The two most important factors in using ANOVA to accept or reject the null hypothesis were calculated.

Table 3: Anova Results of Office Supply Warehouse (1/2)

\begin{tabular}{cccc}
\hline $\begin{array}{c}\text { Source of } \\
\text { Variation }\end{array}$ & SS & Gf & MS \\
\hline Time slots & 137,62 & 10 & 13,762 \\
Days & 7,03 & 4 & 1,758 \\
Interaction & 34,10 & 40 & 0,853 \\
& & & \\
\hline
\end{tabular}

There is a statistical significance to the results if F-value (F) is larger than the $\mathrm{F}$ critical value ( $\mathrm{F}$ crit). Also, these results showed that only time slots have the statistical significance as shown in Table 2. The p-value is less than 0.05 , so was rejected the null hypothesis that there's no difference between the means and the conclusion is that a significant difference does exist.

Therefore, the One-Way ANOVA test has been performed to understand which time slots are relevant and to provide a ranking of them. The Duncan test has been carried out to define the order of importance among the times using the One-Way ANOVA results. The output of this test, shown in Table 5, has defined which time slots have significant differences to each other.
Table 4: Anova Results of Office Supply Warehouse (2/2)

\begin{tabular}{|c|c|c|c|c|c|}
\hline $\begin{array}{l}\text { Source of } \\
\text { Variation }\end{array}$ & $\mathrm{F}$ & P-value & F crit & \multicolumn{2}{|c|}{ Conclusions } \\
\hline $\begin{array}{l}\text { Time } \\
\text { slots }\end{array}$ & 14,92 & $\begin{array}{l}3,4 \mathrm{E}- \\
21\end{array}$ & 1,87 & \multicolumn{2}{|c|}{ p-value $<0,05$} \\
\hline Days & 1,91 & 0,11 & 2,40 & \multicolumn{2}{|c|}{$\mathrm{F}<$ Fcrit } \\
\hline $\begin{array}{l}\text { Interactio } \\
\mathrm{n}\end{array}$ & 0,92 & 0,60 & 1,44 & \multicolumn{2}{|c|}{$\begin{array}{l}\mathrm{F}<\text { Fcrit } \\
\text { p-value }>0,05\end{array}$} \\
\hline \multicolumn{6}{|c|}{ Table 5: Duncan's Multiple Range Test } \\
\hline Time slots & & $\begin{array}{l}\text { Treatments } \\
\text { significant } \\
\text { fferences in } \\
\text { bold) }\end{array}$ & $\begin{array}{r}\text { Diff } \\
\text { bet } \\
m\end{array}$ & $\begin{array}{l}\text { rences } \\
\text { ween } \\
\text { eans }\end{array}$ & $\begin{array}{c}\text { Shortest } \\
\text { significant } \\
\text { range }\end{array}$ \\
\hline \multirow{4}{*}{$8: 30-10: 00$} & & $6: 30-8: 30$ & \multicolumn{2}{|c|}{8,50} & 3,19 \\
\hline & & 0:00-10:30 & \multicolumn{2}{|c|}{7,50} & 3,53 \\
\hline & & 1:00-12:00 & \multicolumn{2}{|c|}{5,33} & 3,49 \\
\hline & & $0: 30-11: 00$ & \multicolumn{2}{|c|}{3,50} & 3,41 \\
\hline \multirow{3}{*}{$\begin{array}{l}10: 30- \\
11: 00\end{array}$} & & $6: 30-8: 30$ & \multicolumn{2}{|c|}{5,00} & 3,53 \\
\hline & & 0:00-10:30 & \multicolumn{2}{|c|}{4,00} & 3,49 \\
\hline & & 1:00-12:00 & \multicolumn{2}{|c|}{1,83} & 3,41 \\
\hline \multirow{2}{*}{$\begin{array}{l}11: 00- \\
12: 00\end{array}$} & & $6: 30-8: 30$ & \multicolumn{2}{|c|}{3,17} & 3,49 \\
\hline & & $0: 00-10: 30$ & \multicolumn{2}{|c|}{2,17} & 3,41 \\
\hline $\begin{array}{l}10: 00- \\
10: 30\end{array}$ & & $6: 30-8: 30$ & \multicolumn{2}{|c|}{1} & 3,41 \\
\hline
\end{tabular}

Different results are achieved by the pharmacy access. Indeed, there are no remarkable differences among the time slots, the days or the weeks there. The truck arrival has a rectangular distribution since the analysis shows that the randomness with which the couriers deliver is very high. Hence, the truck arrival in the drugstore warehouse is a completely random variable with a rectangular distribution.

\section{2. $T O B E$}

The future state is the warehouse management with a storage space of $618,8 \mathrm{~m}^{2}$ and with only one good access for all the hospital. Indeed, during this phase, this gateway will be the unique access to the hospital instead of the actual three (two dedicated to the goods and one two the services). 


\section{Patrone et al. / Advances in Science, Technology and Engineering Systems Journal Vol. 5, No. 1, 256-262 (2020)}

The authors individuated three possible solutions:

1. Scenario 1: internal management of the warehouses.

2. Scenario 2: assigning the warehouses management to an external firm of logistic.

3. Scenario 3: renting of the new warehouse and the procurement of the logistic of the deliveries to the Hospital.

For all the three solutions the following parameters, reported in section 4, have been studied:

- Economic Analysis: the balance between the emerging and the loss costs.

- Impact on Traffic

- Advantages: the point of strength of the scenario.

- Disadvantages: the point of weakness of the scenario.

\section{$\underline{\text { Scenario } 1}$}

This scenario consists in the completely internal warehouse management. There are two main problems in this context. The first is the $62 \%$ less of storage space and the second the unique access to the hospital.

A data extraction on a one-year time frame has been performed in order to calculate the rate of rotation of the goods. The future available space turned out much smaller than the actual one but, thanks to the results performed with the rotation index, it is possible to notice that by increasing this one all the material currently available in the medical devices and office supply warehouse can be incorporated. As shown in the Figure 3, the rotation index of many products is very small or even zero, this means that in a one-year time slot the products are not completely used and their supplies are left. After a Pareto Analysis is possible to establish which products can be moved more often, in order to reduce their stock in the warehouse and to occupy less volume accordingly. It is also possible to determine which products could be put in the higher and less reachable shelves and which ones could be put in the reachable shelves.

\section{Frequency of inventory turnover rate Office Supplies Warehouse}

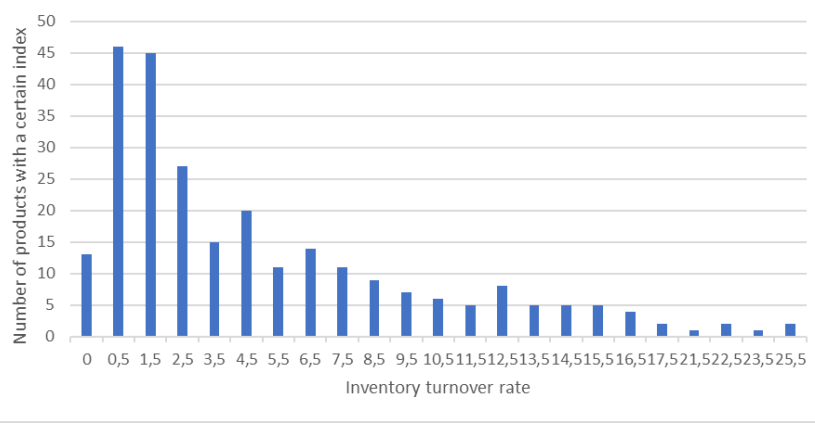

Figure 3: Inventory turnover rate, Office Supplies Warehouse.

Indeed, by increasing the filling percentage in the future shelves, it will be possible to optimize the spaces available and all goods, except drips (IV), can be allocated to warehouses despite the large reduction in space. The IV management will have to be outsourced.

Considering only the contemporary truck arrival of the office supply warehouse and drugstore it is possible to suppose a copresence of about eight trucks in the rush hours. The future truck check-in ramp during the building of the new hospital will receive all the stocks instead of the actual organization. Furthermore, it will have to be the transit point toward many other stocks directed to other wards (e.g. radiopharmaceuticals, catering services and construction site). In order to understand more about the future traffic, an overlap of the trucks has been carried out and has been reported in Figure 4.

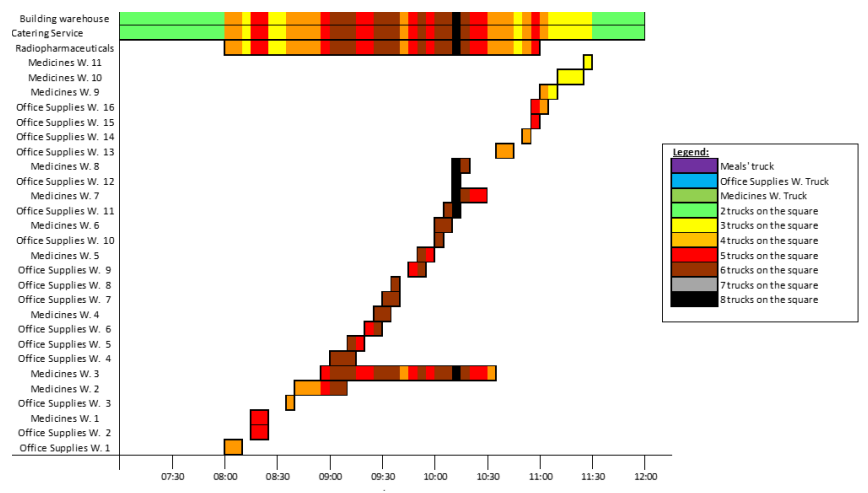

Figure 4: Occupation of the passage square, transitional state.

Figure 4 highlights the co-presence of at least two trucks. In addition, the street on this entrance is a one way one so this is a critical issue to consider.

All the costs involving in this scenario such as the costs for structural costs, outsourcing service for IV, etc. are reported in section 4 .

\section{Scenario 2}

This scenario consists in the outsourcing of the service. This option comprises the delivery of the goods directly to the wards from the external warehouse. There would not be impact on traffic. Indeed, the goods delivery would happen once a day, at the time chosen by the hospital. The delivery time slot would be probably in the afternoon when the most part of the accesses to the hospital have already been done.

A market analysis has been carried out to understand the cost of this service. In addition, the impact on this scenario on the personnel actually dedicated to the warehouse has been studied with a reduction of them through:

- Pensions

- Termination of fixed-term contracts

- Transfer of personnel

$\underline{\text { Scenario } 3}$

In this solution the hospital should rent a warehouse and the service of delivery of material from the rented warehouse to the Hospital. A market analysis has been carried out to understand the 
cost of this service. The warehouse would be managed the hospital with a staff increase.

\section{Results}

The detailed results of the cost analysis implemented are reported in Table 6.

Table 6: Scenario Costs Analysis

\begin{tabular}{|c|c|c|c|}
\hline Cost & Scenario 1 & Scenario 2 & Scenario 3 \\
\hline Staff & $\begin{array}{c}2.700 .000 € \\
\text { (5 years x } \\
30.000 € / \text { year } \\
\text { x } 18 \\
\text { workers) }\end{array}$ & $\begin{array}{c}750.000 € \\
\text { (5 years x } \\
30.000 € / \text { year } \\
x+5 \\
\text { workers) }\end{array}$ & $\begin{array}{c}2.700 .000 € \\
\text { (5 years x } \\
30.000 € / \text { yea } \\
\text { r x } 18 \\
\text { workers) }\end{array}$ \\
\hline $\begin{array}{c}\text { Additional or } \\
\text { diminutive } \\
\text { Staff }\end{array}$ & $\begin{array}{c}7500.000 € \\
\text { (5 years x } \\
30.000 € / \text { year } \\
\text { x } 5 \\
\text { additional } \\
\text { workers) }\end{array}$ & $\begin{array}{c}- \\
1.9500 .000 € \\
(13 \text { workers } \\
\text { less*5years*3 } \\
0.000 € / \text { year })\end{array}$ & $\begin{array}{c}750.000 € \\
\text { (5 years x } \\
30.000 € / \text { yea } \\
\text { r x } 5 \\
\text { additional } \\
\text { workers) }\end{array}$ \\
\hline $\begin{array}{c}\text { Construction } \\
\text { costs }\end{array}$ & \multirow{2}{*}{$\begin{array}{c}€ \\
823.858,00\end{array}$} & $\begin{array}{c}€ \\
105.000,00\end{array}$ & \multirow{3}{*}{$\begin{array}{c}€ \\
275.150,65\end{array}$} \\
\hline $\begin{array}{c}\text { Automated } \\
\text { warehouses } \\
\text { for drugs }\end{array}$ & & & \\
\hline $\begin{array}{l}\text { Wardrobes } \\
\text { and shelving } \\
\text { warehouse }\end{array}$ & $\begin{array}{c}€ \\
20.292,65\end{array}$ & & \\
\hline $\begin{array}{c}\text { I.V. } \\
\text { outsourcing }\end{array}$ & $\begin{array}{c}500.000 € \\
(5 \text { years } x \\
100.000 € / \text { yea } \\
\text { r) }\end{array}$ & & \\
\hline Optical pen & $€ 64,66$ & & $€ 64,66$ \\
\hline $\begin{array}{c}\text { Outsourcing } \\
\text { fee }\end{array}$ & & $\begin{array}{c}5.000 .000 € \\
(5 \text { years x } \\
1.000 .000 \\
€ / \text { year })\end{array}$ & \\
\hline $\begin{array}{c}\text { Rental } \\
\text { warehouse }\end{array}$ & & & $\begin{array}{c}318.000 € \\
(5.300 € / \mathrm{mo} \\
\text { nths per } 60 \\
\text { months })\end{array}$ \\
\hline $\begin{array}{c}\text { Rental } \\
\text { delivery } \\
\text { service from } \\
\text { rented } \\
\text { warehouse to } \\
\text { hospital }\end{array}$ & & & $\begin{array}{c}2.122 .800 € \\
(348.000 \\
€ / \text { years*1,2 } \\
2 \mathrm{VAT}^{* 5} \\
\text { years })\end{array}$ \\
\hline $\begin{array}{l}\text { Total costs } \\
\text { ( } 5 \text { years) }\end{array}$ & $\begin{array}{c}€ \\
4.794 .215,31\end{array}$ & $\begin{array}{c}€ € \\
3.905 .000,00\end{array}$ & $\begin{array}{c}€ \\
6.166 .015,3 \\
1\end{array}$ \\
\hline
\end{tabular}

Table 7 highlights the advantages and disadvantages of each scenario.

Table 7: Scenario Analysis

\begin{tabular}{|c|c|c|}
\hline SCENARIO & ADVANTAGES & DISADVANTAGES \\
\hline $\begin{array}{l}\text { SCENARIO 1: } \\
\text { The exclusively } \\
\text { internal } \\
\text { management }\end{array}$ & $\begin{array}{l}\text { The directly } \\
\text { availability of the } \\
\text { stocks. } \\
\text { Tendering procedure } \\
\text { is not requested. }\end{array}$ & $\begin{array}{l}\text { The rooms' utilization } \\
\text { because they are very } \\
\text { small. The manual } \\
\text { handling is not optimal, } \\
\text { the workforce is expected } \\
\text { to increase. The } \\
\text { medicines' reception and } \\
\text { control will be } \\
\text { problematic because of } \\
\text { the questions that arise } \\
\text { about the responsibility } \\
\text { and the increase of staff. }\end{array}$ \\
\hline $\begin{array}{l}\text { SCENARIO 2: } \\
\text { The exclusively } \\
\text { external } \\
\text { management }\end{array}$ & $\begin{array}{c}\text { The solution is } \\
\text { immediate }\end{array}$ & $\begin{array}{c}\text { Tendering procedures } \\
\text { and the consequently } \\
\text { long time }\end{array}$ \\
\hline $\begin{array}{l}\text { SCENARIO 3: } \\
\text { the partial use of } \\
\text { internal } \\
\text { structures and } \\
\text { the rent of the } \\
\text { external } \\
\text { warehouse }\end{array}$ & $\begin{array}{l}\text { The direct control } \\
\text { over the material. } \\
\text { There is no } \\
\text { immediate expense } \\
\text { for the renovation of } \\
\text { the space necessary } \\
\text { for the transitional } \\
\text { warehouse. }\end{array}$ & $\begin{array}{l}\text { Tendering procedures. } \\
\text { The increase of the } \\
\text { complexity in the } \\
\text { management of remote } \\
\text { staff and the probable } \\
\text { increase of employees. }\end{array}$ \\
\hline
\end{tabular}

\section{Conclusions}

The completely intern solution (Scenario 1) has a very strong impact on the viability. One advantage of this solution is that the items are immediately available and there are no conflicts in the item management, shorter availability time and no tender procedure. The uniquely external solution (Scenario 2) has a low impact on the viability and it is immediate. There is a loss of control in the stocks, confusion in the role of the stock responsibilities etc.

The partially intern solution (Scenario 3) with the rent of an external warehouse has a low impact on the viability. The advantages are the direct control on the merchandise, lack of an immediate disbursement for the restructuring of the spaces. On the other hand, the drawbacks are the increasing in complexity of the remote employee management and a probable increase in personnel.

All the analysis has been subjected to the attention of the Direction. They decided to adopt Scenario 2.

This paper reports a method and it could be applied in all the contexts during the building of a new construction. In the hospital this approach has been used because the management didn't know how to manage the stocks during the building of the new hospital 


\section{Patrone et al. / Advances in Science, Technology and Engineering Systems Journal Vol. 5, No. 1, 256-262 (2020)}

because the spaces for the warehouse were limited and there was an impact on the traffic.

The authors implemented the BPR approach involving all the professionals. This approach achieved the goal because it gives all the elements to the Management to make a decision and all the people feel involved in this phase. In fact, at the end of the project the tensions initially present were completely eliminated.

One possible limitation of the study could be that the market analyses carried out on the August of 2018 could be may change depending on new solutions provided by companies. However, the management of the hospital needed to take a decision on that moment. Nevertheless, the aim of this paper is to provide a method and not an economic estimate. Future research on this topic could be done using discrete event simulation to have more detail on the impact of each solution on the system.

\section{Conflict of Interest}

The authors declare no conflict of interest.

\section{Acknowledgment}

A special thanks to Maria Laura Zizzo, Cinzia Gina Cravisana, Ezio Nicolas Bruno Urbina. Federica Solari, Robrta Clavarino, Mauro Nelli and Carla Elda Fraguglia for their important contribute to this paper.

\section{References}

[1] S. Venkateswaran, "Thesis. Implementing lean in healthcare warehouse operations - evaluation of $5 \mathrm{~S}$ best practice" Louisiana State University and Agricultural and Mechanical College Master's Theses, 2011.

[2] P. Frank, C. Garcia, "Applying Lean Concepts in a Warehouse Operation" IIE Annual Conference and Exhibition. 2004. p. 2819-2859.

[3] S. Holcomb, "Understanding the concept of supply chain resilience" The international journal of logistics management, 20(1), 124-143, 2009.

[4] Collins, H. (2000). Collins English Dictionary. Glasgow.

[5] H. Peck, M.C. Peck, "Building the resilient supply chain" The international journal of logistics management, 15(2), 1-14, 2004.

[6] Y. Sheffi, J.B. Rice Jr. "A Supply Chain View of the Resilient Enterprise" MIT sloan management review, 47(1), 41-48, 2005.

[7] T. A. Saurin, C. B. Rosso and A.L. Colligan "Towards a resilient and lean health care," In: Resilient health care. ROUTLEDGE in association with GSE Research, 2017. p. 3-17.

[8] H. Yalin, and T.E. Yonetimi, "Lean Medical Inventory Management in Hospitals," International Journal of Academic Value Studies (Javstudies), 3, 16-24, 2017.

[9] B.A. Fine, B. Golden, R. Hannam and D. Morra, "Leading Lean: A Canadian Healthcare Leader's Guide," Healthcare Quarterly, 12(3), 32-41, 2009.

[10] A. Yildirim, "Innovative approach to health service materials management" Hestourex World Health Sports Tourism Congress \& Exhibition, 6-9 April 2017, Antalya (33-42).

[11] E.F. Ramly, "Lean Supply Chain contribution toward Lean Health Care," International Conference on Continuous Value Adding based on Lean Thinking in Hospital Management, Tehran, Iran, 30 Nov - 1 Dec 2011.

[12] L. Michailidou, "Healthcare supply chains: a case study of hospital vendor collaborative practices" International Journal of Logistics Systems and Management, 15(2), 288-303, 2013.

[13] E. Aljure, L. Busse, J. Hahn and S. Hayes, "Standardizing and improving the efficiency of Michigan Medicine's supply chain management of hospital supplies," 2017. http://umich.edu/ ioe481/ioe481 past_reports/17W01.pdf

[14] J.C. Chen, C.H. Cheng, P.B. Huang, K.J. Wang, C.J. Huang and T.C. Ting, "Warehouse management with lean and RFID application: a case study," he International Journal of Advanced Manufacturing Technology, 69(1-4), 531542, 2013.

[15] J. Benefield, “CPR For Lean Warehouses," Madison: Advantage Business Media. M., 2015. https://www.inddist.com/operations/article/13763532/cprfor-lean-warehouses
[16] M. Bertolini, F. Bevilacqua, E. Ciarapica, and L. Postacchini "Business process reengineering of drugs storage and distribution: a case study" International Journal of Procurement Management, 8(1/2), 44-65, 2015.

[17] D. Wua, J.E. Tepper, "Possibility of Inventory Pooling in China's public hospital and appraisal about its performance" Applied Mathematical Modelling, 39(23-24), 7277-7290, 2015.

[18] M. Hammer, "Reengineering work: don't automate, obliterate," Harvard Business Review, 68(4), 104-112, 1990.

[19] M. Motta, F. Lega, "Process re-engineering per le aziende sanitarie: una introduzione," Mecosan, 6 (23), 163-165, 1997.

[20] M. Al-Mashari, M. Zairi, "BRP implementation process: an analysis of key success and failure factors," Business process management journal 5(1), 87112, 1999.

[21] P.R. Mosca, "Il progetto quadrato latino," University of Genoa Dipartimento di Ingegneria della Produzione - Gestione degli Impianti Industriali I

[22] D. Montgomery, Design and Analysis of Experiments ( $5^{\text {th }}$ ed.). New York: Wiley, 2001, ISBN 0-7167-9657-0. 